\title{
CULTURA DIGITAL E EDUCAÇÃO, UMA LEITURA DOS ESTUDOS CULTURAIS SOBRE OS DESAFIOS DA CONTEMPORANEIDADE
}

\author{
CULTURA DIGITAL Y EDUCACIÓN, UNA LECTURA DE LOS ESTUDIOS \\ CULTURALES SOBRE LOS DESAFÍOS DE LA CONTEMPORANEIDAD
}

\author{
DIGITAL CULTURE AND EDUCATION, CULTURAL STUDIES AND THE \\ CHALLENGES OF THE CURRENT TIMES
}

\author{
Bruna Damiana HEINSFELD ${ }^{1}$ \\ Magda PISCHETOLA ${ }^{2}$
}

RESUMO: No panorama da cultura digital, o ciberespaço figura como ambiente promotor das redes distribuídas, das múltiplas conexões e da inteligência coletiva, além de atuar como mediador entre pesquisa, estudos, socialização, lazer e consumo. Frente as novas configurações sociais e culturais exercidas pelas tecnologias digitais, urge debater sobre os novos desafios que se apresentam para a educação. $\mathrm{O}$ presente artigo visa problematizar a relação entre sujeitos, novas tecnologias e sociedade e levantar considerações sobre o papel da escola nessa nova organização social, tendo como pano de fundo a perspectiva dos Estudos Culturais. Para tanto, foram analisadas 64 entrevistas com professores do ensino fundamental da rede municipal do Rio de Janeiro acerca do uso das tecnologias digitais no âmbito escolar, com foco em suas práticas pedagógicas e sua visão sobre a relação entre os jovens e as mídias digitais. A análise se encontra dividida em dois eixos principais: I) práticas pedagógicas relacionadas à tecnologia como cultura e, II) inclusão digital, democratização e habilidades para o século XXI. Os resultados apontam para a existência de um distanciamento cultural percebido pelos professores entre si, os alunos e a própria cultura escolar.

PALAVRAS-CHAVE: Educação. Cultura digital. Estudos Culturais. Tecnologias.

RESUMEN: En el panorama de la cultura digital, el ciberespacio figura como ambiente promotor de las redes distribuidas, de las múltiples conexiones y de la inteligencia colectiva, además de actuar como mediador entre investigación, estudios, socialización, ocio y consumo. Frente a las nuevas configuraciones sociales y culturales ejercidas por las tecnologías digitales, urge debatir sobre los nuevos desafíos que se presentan para la educación. El presente artículo tiene por objeto problematizar la relación entre sujetos, nuevas tecnologías y sociedad y plantear consideraciones sobre el papel de la escuela en esta nueva organización social, teniendo como telón de fondo la perspectiva de los Estudios Culturales. Para ello, se analizaron 64 entrevistas con profesores de la enseñanza fundamental de la red

${ }^{1}$ Pontifícia Universidade Católica do Rio de Janeiro (PUC-Rio), Rio de Janeiro - Brasil. Pós-graduanda em Educação pelo PPGE PUC-Rio. E-mail: brunadamiana@gmail.com

${ }^{2}$ Pontifícia Universidade Católica do Rio de Janeiro (PUC-Rio), Rio de Janeiro - Brasil. Professora adjunta no Departamento de Educação. Coordenadora do grupo de pesquisa Formação Docente e Tecnologias (ForTec/PUC-Rio). E-mail: magda@puc-rio.br 
municipal de Río de Janeiro acerca del uso de las tecnologías digitales en el ámbito escolar, con foco en sus prácticas pedagógicas y su visión sobre la relación entre los jóvenes y los medios digitales. El análisis se encuentra dividido en dos ejes principales: I) prácticas pedagógicas relacionadas con la tecnología como cultura y, II) Inclusión digital, democratización y habilidades para el siglo XXI. Los resultados apuntan a la existencia de un distanciamiento cultural percibido por los profesores entre sí, los alumnos y la propia cultura escolar.

PALABRAS CLAVE: Educación. Cultura digital. Estudios Culturales. Tecnologías.

ABSTRACT: In the digital culture scenario, cyberspace stands as an environment that promotes distributed networks, multiple connections and collective intelligence, in addition to acting as a mediator between research, studies, socialisation, leisure and consumption. Faced with the new social and cultural configurations exerted by digital technologies, it becomes urgent to discuss the new challenges concerning education. The present paper aims to problematize the relationship between individuals, new technologies and society, and to raise questions about the role of the school in this new social organisation, having as background the perspective of Cultural Studies. To do so, we analysed 64 interviews with elementary school teachers of Rio de Janeiro's public network about the use of digital technologies in class, focusing on their pedagogical practices and their vision on the relationship between youth and digital media. We divided the analysis into two main axes: I) educational practices related to technology understood as culture and, II) Digital inclusion, democratisation and skills for the 21st century. The results point to a teacher's perception of the existence of a cultural detachment amid themselves, the students and the school itself.

KEYWORDS: Education. Digital culture. Cultural Studies. Technologies.

\section{Introdução}

Em 1997, ao publicar a primeira edição de Cyberculture, que viria a alcançar o Brasil em 1999, Pierre Lévy previa que, dentro de alguns anos (em “algumas dezenas"), o ciberespaço, com sua proliferação de conexões e redes distribuídas, comunidades virtuais, simulações, imagens, textos e diversos signos, seria o novo mediador da inteligência coletiva da humanidade. Os saberes estariam acessíveis nos mundos virtuais, no chamado ciberespaço, através do qual as comunidades conheceriam, construiriam, significariam e resinificariam não somente objetos, teorias e informações, mas também a si mesmas como coletivos inteligentes.

Hoje, em 2017, quase duas décadas após as previsões de Lévy, presenciamos a mobilidade e a ubiquidade das conexões via internet. Superamos o "estar conectado", alcançando o patamar do "ser conectado". Vivemos imersos na cultura digital e não 
estamos estagnados: internet das coisas, web semântica, sensores RFID, mobile tags. Em um futuro próximo, qualquer objeto estará conectado à internet, produzindo e transmitindo dados de seus usuários, em uma comunicação de muitos para muitos. Hoje, o ciberespaço já pode ser considerado o último dos shoppings centers, o parque de diversões mais sedutor, a universidade das universidades e a biblioteca das bibliotecas. Mas, se hoje somos seres cíbridos, imersos em um novo panorama cultural, em que posição se encontra a escola nesse espaço?

\section{As tecnologias digitais como ressignificação cultural}

Para se abordar o conceito de cultura digital, primeiramente faz-se necessário esclarecer o nosso entendimento do conceito de cultura. Adotamos como ponto de partida a análise de Canclini (2005), que apresenta duas vertentes de significação do termo. Por um lado, no uso cotidiano da palavra, a cultura é compreendida como sinônimo de erudição, informação e educação. Essa distinção entre cultura e civilização tem suas raízes na filosofia idealista e se constrói historicamente como afirmação dos valores e dos gostos ocidentais, principalmente europeus, em detrimento de outros conhecimentos considerados menos dignos de serem difundidos. Por outro lado, há nas ciências sociais uma tentativa de definir a cultura como um conceito científico, em contraposição com outros conceitos, primariamente o de natureza e o de sociedade. A primeira distinção, entre cultura e natureza, serviu historicamente para atenuar o etnocentrismo (e eurocentrismo) e relativizar o conceito, admitindo que é cultura tudo o que for criado pelos homens em qualquer sociedade, de qualquer momento histórico. Porém, apesar de sua importância do ponto de vista filosófico e antropológico, essa definição, por sua abrangência, ainda deixa espaço a muitas interpretações subjetivas. Com isso, surgiu a reflexão sobre a oposição entre cultura e sociedade, que fundamentalmente considera a cultura como um "resíduo" das análises das estruturas sociais (CANCLINI, 2005, p. 32). Seria esse o valor simbólico dado aos objetos, crenças, princípios e demais experiências, que vai além do seu valor de uso, constituindo assim o fundamento dos rituais que ocorrem em cada sociedade. Em outras palavras, o valor simbólico dos objetos materiais e das ações humanas é criado através dos processos de significação e ressignificação social (BARATTO; CRESPO, 2013). Nesse sentido, a cultura corresponde a determinado conjunto de condições sociais que 
(re)produz, transforma e cria sentidos e valores. Em síntese, a cultura se configura como "conjunto de processos sociais de produção, circulação e consumo da significação na vida social" (CANCLINI, 2005, p. 34). Ou seja, toda ação humana significa algo e participa de alguma forma nas interações sociais: a cultura é parte das práticas sociais, está vinculada à sociedade, mas não equivale à totalidade da sociedade. Essa definição sócio semiótica de cultura é suficientemente operacional do ponto de vista científico e, portanto, compartilhada por autores de várias disciplinas. Seguiremos essa linha de raciocínio para redefinir o conceito de cultura pensando nos tempos atuais.

Ao se conceituar cultura digital, considera-se a alteração das relações culturais quanto ao entrosamento entre sujeitos e mídias de informação e comunicação, surgida da ruptura na forma como a informação era até então concebida, (re)produzida e difundida. Essa metamorfose, como se observa, caminhou na direção da mobilidade e da ubiquidade. A cultura digital está relacionada à comunicação e à conectividade global, ao acesso e à produção de conteúdo de forma veloz, interconectada, autônoma e mediada pelo digital, através das redes distribuídas (CASTELLS, 1999; UGARTE, 2008). Nesse novo cenário, ubíquo e híbrido, com conexões cada vez mais rápidas e mais expandidas, há o apagamento das linhas limítrofes entre o que se considera "real" e o "virtual", convergindo para a desterritorialidade. A cultura digital se caracteriza, portanto, pela reestruturação da sociedade, oportunizada pela conectividade, emergindo transversalidade, descentralização e interatividade. Trata-se de um novo contexto, em que as tecnologias digitais, tendo a Internet como pano de fundo, aparecem como meios responsáveis por uma nova tessitura social (GABRIEL, 2013; SETTON, 2015). É importante destacar que a mudança vai além do tecnicismo, mantendo relações dialógicas e dialéticas com noções político-sociais, como a ciberdemocracia, a inclusão e a ética hacker, bem como manifestações de cunho artístico com identidades próprias, autônomas, cuja organização tem como base os princípios de colaboração, horizontalidade e descentralização, favorecendo a inteligência coletiva, problematizando o que se entende como democracia, direitos autorais e relação entre público-privado-social (CAZELOTO, 2009; LEMOS, 2009; LESSIG, 2008). É evidente o valor simbólico que essas ações assumem na sociedade atual e a necessidade de se estudar as tecnologias digitais de um ponto de vista cultural. A abordagem que apresentamos a seguir surge da aplicação da perspectiva teórica dos Estudos Culturais ao momento histórico atual. 


\section{Os estudos culturais e a cultura digital}

A partir do século XX, explica Stuart Hall (1997), principal expoente dos Estudos Culturais, passou-se a viver uma revolução cultural, a mídia assumindo singular importância no que diz respeito à organização da sociedade moderna tardia, como uma condição constitutiva da vida social. Nas palavras de Hall (1997, p. 4): "a cultura é agora um dos elementos mais dinâmicos - e mais imprevisíveis - da mudança histórica no novo milênio". Através da revolução tecnológica, expandiu-se também a circulação e a troca cultural. Pode-se dizer que não há mais uma identidade somente local, objetivada, sem quaisquer relações com o global. Entende-se, ainda, que uma cultura "global”, fundamentada na difusão e homogeneização dos valores ocidentais pelo mundo inteiro, necessita também das diferenças locais para que possa prosperar. Com isso, o conceito de cultura incorpora novas possibilidades, sendo declinado em sua flexão plural e adjetivada, culturas (COSTA et al., 2003). A cultura unificada e hegemônica toma a forma de novas identificações heterogêneas e adaptações localizadas, de hibridismos que sintetizam elementos de culturas múltiplas, não se limitando ou se reduzindo a nenhuma delas. Posto isto, torna-se mandatório compreender que revoluções culturais globais causam impacto sobre os modos de viver, seus sentidos e ressignificações, aspirações e mesmo sobre culturas locais, e que geram, como frutos, mudanças sociais e deslocamentos culturais.

Os Estudos Culturais buscam a compreensão dos processos de comunicação que influenciam essas mudanças, entendendo o receptor não como sujeito passivo, mas como agente nesse processo social, sendo a recepção dos produtos da mídia variável de acordo com a percepção singular do indivíduo. Procuram diferenciar os conceitos de padronização e homogeneização cultural, valorizando as possibilidades de interpretação local que os sujeitos fazem dos produtos e das mensagens veiculadas pelas mídias. Dessa forma, a abordagem dos Estudos Culturais afasta-se do pensamento sobre o caráter homogeneizador e manipulador das mídias, abrindo espaço para as contradições sociais e para os conflitos culturais potencializados pelas tecnologias digitais (TERUYA, 2009).

Uma vez que os Estudos Culturais têm o compromisso de analisar a relação entre a mídia e os outros aspectos culturais da sociedade contemporânea, a partir dos anos 1990 e com a profusão das tecnologias digitais, esses estudos passaram a investigar também demais assuntos vinculados à tecnologia, especialmente em função 
da internet. Nessa perspectiva, considera-se que tanto o uso quanto a apropriação das tecnologias digitais são, antes de tudo, produções culturais de determinada sociedade e seu caráter histórico, sendo as tecnologias elementos centrais da produção e reprodução de cultura. Assim, frente à hipótese da existência de uma cultura específica advinda da presença dos meios eletrônicos na sociedade atual, uma cultura digital, "o termo digital estaria representando uma forma particular de vida de um grupo ou de grupos de sujeitos em um determinado período da história" (BORTOLAZZO, 2016, p. 11). Sendo a cultura digital pensada como um marcador cultural, que envolve tanto os artefatos digitais quanto sistemas de significação e comunicação distintos, capazes de descrever o modo de vida contemporâneo.

Partindo da centralidade da cultura, Hall (1997) pontua que são duas as dimensões da cultura: a substantiva e a epistemológica. A dimensão substantiva diz respeito ao lugar da cultura na organização das atividades sociais e suas relações culturais e institucionais, ou seja, é a declinação empírica e concreta de todos os aspectos culturais de uma dada sociedade em uma determinada localidade geográfica e momento histórico. Por outro lado, a dimensão epistemológica diz respeito aos modos como a cultura é utilizada para transformar nossa compreensão e explicação para os fenômenos do mundo. Trata-se do "filtro", constituído por modelos teóricos e códigos de significado, que aplicamos a uma realidade sócio histórica determinada, para podermos interpretar os eventos sociais e as ações alheias e, assim, regular a nossa própria conduta com relação aos outros indivíduos. A linguagem é o meio através do qual a dimensão epistemológica se constitui, pois é a linguagem que determina uma forma específica de classificar os objetos e lhe atribuir significados.

Ao considerar a dimensão substantiva com relação à sociedade vigente e ao panorama da cultura digital, tem-se o destaque para as transformações ocorridas, tanto nas esferas econômica e industrial como na esfera sociocultural, dados os novos domínios tecnológicos e a ascensão das tecnologias da informação e da comunicação. Tem-se como fruto uma força de mudança histórica global, com foco nas transformações culturais do cotidiano, em especial com relação às identidades pessoais e sociais.

Por outro lado, alguns autores, como Costa et al. (2003), consideram que a dimensão epistemológica diz respeito ao que chamam de "virada cultural". A virada cultural refere-se ao poder instituidor dos discursos culturais, sendo esses discursos como os programas de TV, canais do Youtube, bandas de música ou manifestações 
artísticas - não apenas artefatos produtivos, mas práticas de representação, criadoras de sentidos. Nessa perspectiva, considerando o panorama sociocultural vigente, amplia-se também o conceito de realidade, indo além das ideias de espaço, tempo e lugar estáveis. A realidade, desde sempre mediada pela linguagem e os códigos criados por ela, é hoje mediada também pelas culturas e pelas linguagens das mídias. Explica Hall (1997, p. 5):

\begin{abstract}
A cultura está presente nas vozes e imagens incorpóreas que nos interpelam das telas, nos postos de gasolina. Ela é um elemento chave no modo como o meio ambiente doméstico é atrelado, pelo consumo, às tendências e modas mundiais. É trazida para dentro de nossos lares através dos esportes e das revistas esportivas [...]. Elas mostram uma curiosa nostalgia em relação a uma comunidade imaginada, na verdade, uma nostalgia das culturas vividas de importantes locais que foram profundamente transformadas, senão totalmente destruídas pela mudança econômica e pelo declínio industrial.
\end{abstract}

Isso é ainda mais evidente com o advento das tecnologias da informação e da comunicação e dos mundos virtuais que são criados por elas. Conforme Bannell et al. (2016), os ambientes virtuais caracterizam um novo significado da presença do sujeito, abrindo espaço para sensações, experiências e possibilidades inéditas, e para novas formas de aprendizagem.

É inevitável que essas mudanças tenham também um impacto na dimensão pedagógica de uma sociedade. Pensando no protagonismo juvenil no ambiente escolar, Naumann (2016, p. 26) propõe três aspectos da cultura digital que devem ser levados em consideração nas práticas pedagógicas: “(i) a possibilidade da autoria como produção própria de conhecimento; (ii) a oportunidade de acesso à informação e de elaboração autoral dos conteúdos acessados, como forma de participação e protagonismo; (iii) a autoria como inclusão digital". Segundo Costa et al. (2003), os Estudos Culturais podem auxiliar no entendimento das mudanças em campo pedagógico, oportunizando uma ressignificação de questões como identidade, discurso e representação, que passam a ocupar o primeiro plano, e também na extensão das noções de educação, pedagogia e currículo para além do ambiente escolar. Entende-se que a perspectiva apresentada pelos Estudos Culturais pode ser muito interessante para a reflexão acerca dos novos panoramas educacionais do século XXI e seus iminentes desafios.

\title{
Os estudos culturais e a educação
}


Ao relacionar os Estudos Culturais às tecnologias digitais e educação, na perspectiva da cultura digital, educadores e aprendentes trabalhariam em consonância com as tecnologias digitais, a escola assumindo o papel de orientar, guiar e apoiar os esforços dos alunos frente aos novos significados e às estruturas do mundo virtual, além de explorar suas potencialidades. Levar-se-ia em consideração não somente o conhecimento escolar, mas a experiência prévia do aprendente, seu cotidiano e conhecimentos construídos a partir dele (BANNELL et al., 2016; PISCHETOLA, 2016; SELWYN, 2011a, 2011b). Dessa forma, não se limitaria à utilização da mídia como recurso didático, mas, sim, como viabilizadora da problematização das narrativas que dão sentidos à cultura vigente. $\mathrm{O}$ foco não estaria na relação substantiva entre cultura $\mathrm{e}$ organização da sociedade, mas nos aspectos epistemológicos que, como explicamos acima, delimitam as interpretações culturais. Nesse sentido, as mídias seriam percebidas como linguagens, capazes de codificar, recodificar e interpretar todos os fenômenos do social.

A partir dessas considerações, nos perguntamos: em um cenário em que é possível acessar informação, aprender, colaborar e trocar conhecimento via redes digitais, através de atividades sociais cotidianas, no qual não há uma cultura homogênea a ser transmitida para os indivíduos, mas, sim, ululantes multiculturalismos, e em que a relação espaço-tempo de aprendizagem sofreu profunda alteração graças aos adventos tecnológicos e às novas maneiras de o homem se relacionar com a informação, qual seria a função da educação? Qual será, especificamente, o papel da instituição escolar, nessa nova sociedade? De que forma estaremos formando cidadãos para a sociedade futura?

\section{Desafios da cultura digital para a educação}

Em face ao novo quadro, na era da informação e da cultura digital, emergem grandes desafios para a educação, dentre os mais marcantes a necessidade de a escola propiciar o desenvolvimento das habilidades necessárias à atuação cidadã em sociedade e a urgência de serem exploradas as potencialidades das redes digitais. Faz-se necessário entender, então, a forma de os alunos se relacionarem no mundo contemporâneo, tanto entre si quanto com a informação. 
Com isso, colocam-se algumas questões, para crucial reflexão: como os professores podem auxiliar seus alunos no desenvolvimento dessas habilidades? Como incluir as novas mídias digitais em sala de aula, reduzindo o estranhamento e a discrepância entre o ambiente escolar e o cotidiano dos indivíduos? Como considerar na prática docente as novas formas de se relacionar com a informação? Como criar um ambiente de aprendizagem que favoreça a autonomia, a autoria e a emancipação? Como explorar todas essas potencialidades?

Em primeiro lugar, constatamos que quaisquer que sejam as reflexões sobre o futuro da educação sob o panorama da cibercultura, elas devem ter como base a análise e o entendimento dessa transformação da relação com o saber (LÉVY, 2014). Novos desafios surgem ao pensarmos em como o educador para essa nova sociedade poderia atender a experiências tão múltiplas, sob um panorama tão recente e volúvel. Os então novos recursos midiáticos, embora possibilitem novas formas de se ver, ler e interpretar os universos culturais, também sobrecarregam os indivíduos com excesso de informações, fragilizando sua capacidade de conceituar, de pensar e de se estabelecer relações dialéticas de compreensão do recorte da realidade social. Vista a rapidez e o dinamismo das metamorfoses tecnológico-sociais, a definição dos conhecimentos e das habilidades necessárias se mostra uma árdua tarefa no campo educacional. Nesse sentido, muitos autores problematizam quais seriam as habilidades essenciais para a atuação cidadã e quais as competências estratégicas para essa nova era (BUZATO, 2010; GABRIEL, 2013; GEE, 2015; GILSTER, 1997; JENKINS 2006, 2009, LEMKE, 2010; LIVINGSTONE, 2011; PRETTO E PINTO, 2006; TERUYA, 2009). Parece haver consenso entre os especialistas no que diz respeito à tônica dessas habilidades, que gira em torno do desenvolvimento do pensamento crítico, da habilidade de solução de problemas, do entendimento e da apropriação do funcionamento das redes colaborativas, em especial das possibilidades da inteligência coletiva, da adaptabilidade e da resiliência, da criatividade, da curiosidade, da iniciativa e do empreendedorismo, e, não menos importante, das faculdades de pesquisa, acesso, análise e avaliação das informações disponíveis. Pretto e Pinto (2006) também ressaltam que, dada a formação recebida e o ambiente em que se performavam as atividades cotidianas até então, os sujeitos não estão habituados a atuar de forma colaborativa, como se considera hoje ser o ideal. Não raro vê-se ainda a lógica da hierarquia e da dependência de "instâncias superiores" para a tomada de decisões e validação de atitudes e conhecimentos. 
Um segundo aspecto relevante ao considerar os desafios da cultura digital para a educação, especialmente no Brasil, diz respeito ao acesso democrático às tecnologias, também conhecido como problema da inclusão digital. Perpassando as ideias de Cazeloto (2009), pode-se dizer que há duas visões distintas ao relacionarmos democracia e internet: a primeira a respeito à igualdade de acesso a essas tecnologias, a qual o autor chama de "democratização $d a$ internet", enquanto a segunda diz respeito ao conceito de ciberdemocracia, considerada a "democratização pela internet". Embora havendo a noção dessa distinção, ainda hoje é possível observar que se prioriza a primeira visão, democratizando o acesso a hardwares e softwares, equipando escolas, sem genuína problematização daquilo que, de fato, está sendo democratizado. Nesse sentido, percebe-se que há a máscara da inclusão social, sem que se articulem demais elementos que de fato favoreçam trocas e oportunidades sociais, culturais ou mesmo econômicas. Trata-se de uma visão tecnicista, reducionista, e que exime a escola de propostas pedagógicas que favoreçam a verdadeira participação e apropriação das tecnologias pelos atores envolvidos no processo de ensino-aprendizagem. Esse aspecto se torna relevante para a discussão dos desafios para a educação, uma vez que tal condição de "inclusão" determina também qual será o uso real dos equipamentos, distribuídos como meras ferramentas, de forma mecânica e autoritária, impondo determinadas relações entre os sujeitos e as máquinas. Com efeito, os resultados dessas políticas são, em verdade, perversos (BONILLA \& PRETTO, 2011; PISCHETOLA, 2016).

Em suma, os dois aspectos acima mencionados - reconfiguração da relação com o saber e inclusão digital como democratização pela internet - apresentam-se como desafios similares para a educação, com relação à apropriação tecnológica e exploração de seus potenciais. Em nosso entendimento, trata-se de um único grande desafio: encarar as tecnologias digitais como veículo, produção, transformação de cultura. Isso é ainda mais evidente ao pensarmos nas jovens gerações, que crescem imersas nas tecnologias digitais. Por um lado, suas práticas de busca, acesso e elaboração da informação através das tecnologias nos dizem respeito às mudanças na relação com o saber e a aprendizagem. Por outro lado, essas mesmas práticas nos fazem pensar nao significado da inclusão social na contemporaneidade. Com isso, urge a necessidade de a escola também reconhecer os impactos culturais que as novas tecnologias trazem para a sociedade contemporânea. Pois é a partir desse reconhecimento que a educação pode 
repensar seus métodos, seus objetivos, suas relações e formas de organização, e propor práticas pedagógicas capazes de dar conta desses desafios.

\section{Professores e cultura digital: uma pesquisa em oito escolas do Rio de Janeiro}

Apresentamos para este trabalho um recorte de uma pesquisa acadêmica institucional desenvolvida ao longo do ano escolar de 2015, que investigou práticas pedagógicas com uso de tecnologias em oito escolas de ensino fundamental da rede municipal do Rio de Janeiro. As instituições foram indicadas pela Secretaria Municipal de Educação local (SME-RJ), por seu pioneirismo e relevância no trabalho com projetos envolvendo o uso de diferentes tipos de mídias. A pesquisa, de cunho qualitativo, utilizou o instrumento da entrevista semiestruturada com 64 professores das escolas campo (oito professores de diferentes disciplinas por cada escola).

A proposta de análise das falas dos professores detém-se na busca por estratégias para superar os desafios postos pela cultura digital no âmbito escolar, em consonância com a fundamentação teórica dos Estudos Culturais. Em particular, dois aspectos específicos foram pesquisados: (1) as tecnologias digitais como possível veículo de construção de saber e lugar de aprendizagem para as jovens gerações; (2) as tecnologias digitais como elemento que favorece a inclusão social e a democratização do acesso ao conhecimento. Com esse escopo, buscou-se identificar nas falas dos professores sua visão sobre aspectos culturais na relação entre os jovens e as mídias digitais, em especial quanto à manipulação dos conteúdos online feita pelos jovens, à colaboração e à cultura de participação, bem como quanto à relação desses aspectos com as práticas pessoais de (auto)aprendizagem.

A análise das falas foi feita com base na Teoria Fundamentada em Dados (Grounded Theory), criada por Glaser e Strauss em 1967, extremamente eficaz, mas pouco utilizada nos estudos nacionais. Conforme essa metodologia, a codificação dos dados segue diferentes etapas: (i) codificação aberta, (ii) codificação axial ou formação e desenvolvimento do conceito; (iii) codificação seletiva ou modificação e integração do conceito e delimitação da teoria. A metodologia baseia-se nos dados produzidos no campo, com o objetivo de gerar explicações para ações dos indivíduos dentro de um contexto social de estudo (CASSIANI et al., 1996). Sendo assim, seguem os resultados principais de nossa análise. Além dos focos de pesquisa mencionados acima - 
tecnologias e construção do saber e inclusão digital -, emergiu uma terceira categoria, que diz respeito à visão que os professores têm de seus alunos, imersos ao mesmo tempo na cultura digital e na escola. Apresentamos primeiramente essa categoria, para contextualizar a percepção dos professores participantes da pesquisa

\section{A cultura digital, os jovens alunos e a escola}

Para podermos aprofundar os estudos com relação às novas formas de aprendizagem e às práticas pedagógicas da cultura digital, tanto de alunos quanto de professores, iniciamos nossos comentários sobre as entrevistas elencando, adiante, algumas falas que refletem o entendimento dos entrevistados quanto à relação entre os alunos e as tecnologias digitais.

Porque como eu falei antes, hoje em dia, eles já nascem mexendo em botõezinhos, seja no computador, na televisão, no rádio, no som, no aparelho do som em casa, no jogo... (01.04)

Mas isso é uma questão dessa geração, que é muito rápida, o dia é muito curto, tudo tem que ser muito depressa. E no caso as várias formas de mídias vão levando a nós acharmos que o tempo está muito curto. A velocidade é muito rápida desses mecanismos. (01.08)

Acho que as crianças hoje são de uma época diferente, é claro. [...] Eles têm essa sede. Eu acho que já vem no DNA, eu não sei. [...] Para eles isso já é normal. Eles já têm aquele domínio todo. (02.05)

Eu acho que a mídia está na vida deles, [...] eles estão lá o tempo inteiro, eles fotografam, eles mandam mensagens... é uma sociedade tecnológica. (02.08)

A gente tá vivendo um momento da era tecnológica e cada vez mais avançada. Os nossos alunos, em contrapartida, se servem desse instrumento, eles mexem muito mais com as questões de mídia do que eu mesmo, né? Entendem melhor isso do que eu próprio. (04.03)

Então, eu vejo que é uma relação extremamente importante, porque as gerações que vem agora dos alunos já estão inseridos. Eu costumo até brincar com eles, dizendo que eles estão nascendo com chip. Então, já nascem inseridos nisso, já mexem com as tecnologias e com as mídias de maneira geral. (08.03)

Observa-se que, nessas falas, os professores elencam como características base das gerações de jovens alunos do século XXI a agilidade do acesso às informações, a 
velocidade da troca e do compartilhamento, além de um domínio técnico das tecnologias digitais, tido como inerente. É possível perceber, de início, que há certo distanciamento por parte dos entrevistados das práticas cotidianas desses jovens. Corroborando com a ideia de que há um distanciamento dessas práticas, cerca de metade dos professores entrevistados (30/64) menciona em seus discursos a necessidade de a escola acompanhar as mudanças socioculturais de uma era imersa nas tecnologias digitais, englobando e se apropriando dessas transformações, já familiares ao cotidiano do aluno, sendo as mídias digitais um dos elementos centrais nesse cenário. Com relação ao aspecto cultural, as falas desses professores refletem, em grande parte, uma transformação inevitável, como se a cultura das mídias agisse como um predador e, a cultura "predecessora", sua presa.

Eu acredito que a mídia precisa estar inserida no ambiente escolar, porque numa sociedade como a de hoje a gente não tem como eliminar a mídia da rotina do aluno, então não tem como ele viver 24 horas com a mídia fora da escola e dentro da escola a gente querer excluir isso dele, acho meio inviável. (03.01)

A escola precisa estar conectada com todas as transformações que acontecem no mundo. A gente não trabalha com uma educação ou com o mundo que parou. (05.01)

Essa utopia de que a informática vai mudar o mundo, não, já está aí, já mudou, vamos adiante e fazer o que mais pode contribuir. (05.03)

A mídia hoje é uma realidade. [...] Não tem como a gente ir contra isto e acho que o professor e a escola podem ter um papel mediador entre essa quantidade de informações. (06.03)

Em nosso entendimento, esses dados dialogam com Bortolazzo (2016) e Lévy (2014) na medida em que identificam a crença em uma cultura oriunda da apropriação das tecnologias digitais em dado período de nossa história.

Salientamos a fala do entrevistado 05.03, a seguir, ao mencionar seu entendimento das tecnologias como práticas culturais, se aproximando bastante da abordagem dos Estudos Culturais. Nessa visão, não há uma prática de uso das tecnologias entendida como mais ou menos "adequada". Há simplesmente um entendimento de que todas as práticas dos jovens com as novas ferramentas constituem, de fato, sua cultura.

[A mídia] é uma cultura. Na nossa sociedade hoje, ela é uma ferramenta, mas ela também faz parte da cultura, porque as crianças de hoje não conheceram o mundo sem a informação em tempo real, o 
mundo para elas é em tempo real, o mundo para elas é globalizado, então elas não conseguem imaginar como seria o mundo sem isso, porque elas cresceram no mundo onde aconteceu um negócio do outro lado do mundo e você já está sabendo na mesma hora. Você quer saber uma coisa então tu vai no Google. Tu tá conversando uma coisa com o teu colega, não tem mais aquela coisa de tu não saber quem está certo e ficar na dúvida até chegar em casa. A gente pega o celular na mesma hora e olha, e vê quem estava certo, já vê a informação. A estrutura mental deles se forma de uma forma completamente diferente, na minha opinião. (05.03)

\section{A construção de saber, entre tecnologias e escola}

Um questionamento constante dos professores diz respeito à forma que os alunos utilizam as mídias digitais em seu cotidiano. Muitos dos entrevistados entendem - com certa frustração - que seus alunos as utilizam exclusivamente para o lazer, sem que haja compreensão real de suas potencialidades. Isso indica que, no entendimento desses professores, há uma grande digressão entre a relação pessoal desses alunos com as mídias digitais e o uso pedagógico tido como "adequado". Em determinados momentos, comenta-se também a mediação entre alunos e tecnologias digitais como uma prática necessária, buscando potencializar a utilização dessas mídias para fins didáticos.

Quando você começa a observar o que realmente os alunos conhecem da tecnologia vai só até a parte de usar o Facebook e, talvez, o Whatsapp, passou disso eles não têm muito contato. Às vezes eles não sabem pesquisar, não sabem selecionar a matéria. (01.02)

Nós contextualizamos a aula conforme a mídia e, principalmente, fazemos ele refletir sobre a prática dessa mídia. Afinal de contas, há quanto tempo ele usa essa mídia? Quanto tempo que ele usa pra estudar? Será que ele tá usando a mídia para o estudo, será que ele tá fazendo isso, tá usando a mídia para o estudo? [...] Ele só usa a mídia para compartilhar fotos, vídeos? (03.05)

Não adianta a gente pedir uma pesquisa para o aluno, que eles vão lá no Google, vão botar aquele termo e vão aparecer sites diversos que, às vezes, não tem nada a ver com o que a gente tá propondo, então a gente tem que direcionar o aluno. (02.01)

Ao longo da pesquisa, percebemos que os professores reconhecem a necessidade de tornar a sala de aula um espaço mais atraente, na tentativa de superação desse gap cultural entre aluno e escola. Ao falarem de suas práticas pedagógicas os professores 
destacam, por exemplo, a importância do uso de recursos visuais, buscando maior contextualização do conteúdo pedagógico sendo apresentado e sua aproximação com a realidade do aluno. Outro elemento que surge na fala de alguns entrevistados é a diversificação dos materiais que podem ser utilizados com fins didáticos.

Então, o que há 20 ou 30 anos atrás não seria considerado material de ensino, hoje é considerado: uma propaganda, um folheto, um papel, um vídeo que passa no Youtube, um desenho que você vê tudo pode vir para a sala de aula. (01.02)

Diferente de como era um tempo atrás que a gente só trabalhava com livro, fontes escritas, jornal, revista. Hoje em dia a gente tem uma gama de possibilidade. Eles visitam sites que para eles são superinteressantes e que eles não tinham acesso anteriormente. Sem sair de casa ou da escola. (01.05)

Algumas dessas informações que por eles passam desapercebidas no Facebook, eu pego a mesma postagem de um Face, trago para sala de aula e trabalho ali no português em cima de um texto que aparentemente não serviria para nada... Mas dentro de uma imagem tiro muita coisa. Basta uma imagem, uma charge e trabalho muita coisa, um vídeo, muita coisa. (04.01)

O uso pedagógico de vídeos diversos é citado de forma unânime pelos professores como uma prática constante e facilitadora do processo de ensino e aprendizagem e da compreensão de conceitos, em especial nas disciplinas que requerem um grande potencial de abstração. Todavia, os argumentos utilizados recaem, em geral, na facilidade e na agilidade do vídeo e na forma como essa mídia capta a atenção dos alunos, havendo ausência de justificativa aprofundada sobre essa escolha. Percebe-se que, na maior parte das falas, embora os professores indiquem a necessidade de a escola acompanhar o ritmo das transformações tecnológicas e afirmem que isso é necessário para uma melhor aprendizagem dos alunos, há uma dificuldade em estabelecer essa relação com sua prática docente de forma crítica. Nesse sentido, percebemos que a tecnologia é encarada principalmente como uma ferramenta de apoio à prática pedagógica, como um auxílio que torna a aula mais atrativa, motivando os alunos a se interessarem pelos conteúdos apresentados. Certamente, a sala de aula é um espaço de diálogo entre professor e aluno e a perspectiva de encurtar as distâncias entre as culturas é um argumento válido para o uso de tecnologias. Porém, nessa visão, está implícito que as práticas pedagógicas permanecem inalteradas, ou ao menos pouco afetadas pela presença de tecnologias. 
Outra prática com relação às tecnologias digitais surge ao analisarmos os discursos dos professores, nos remetendo ao indicado por Selwyn (2011a) como o que seria o "uso para a manutenção do controle" ou, como indicado por Pischetola e Heinsfeld (2017), um “estilo motivacional controlador”. Na perspectiva desses autores, professores preocupados com questões de autoridade e disciplina relatam usos das tecnologias digitais como uma forma de recompensa pelo bom comportamento do aluno ou completude de suas tarefas em sala de aula, ou seja, como elemento motivacional extrínseco e não como artefato cultural. Um dos depoimentos coletados em nossa pesquisa resume essa visão e reafirma a tendência de alguns professores utilizarem as tecnologias com um estilo controlador:

\section{Enquanto eu estou na aula, estou ali prestando atenção em alguma coisa, eu não posso usar, mas se eu quero buscar uma informação de algo que eu achei interessante, em uma hora que está do intervalo, quando terminei a atividade, não tem porque não. Então, eu na minha sala deixo quando eles terminam a atividade. (05.03)}

Trabalhos com blogs, fanpages em redes sociais, música, animações e fotografia foram citados pelos entrevistados como práticas pedagógicas cotidianas. Contudo, a maioria dos professores entrevistados considera determinados costumes do cotidiano dos alunos como negativos para o ambiente escolar, em especial o uso do smartphone, alegando que o utilizam apenas para ouvir músicas e conversar nas redes sociais, até mesmo durante as aulas. Boa parte desses professores pondera que o "uso controlado" para pesquisas poderia ser proveitoso, dada a ubiquidade e agilidade do processo. Porém, é difícil conciliar novas formas de aprendizagem, novos percursos de acesso à informação e de pesquisa, com procedimentos pedagógicos totalmente controlados.

Consideramos importante, nesse momento, voltar a atenção aos aspectos considerados negativos elencados pelos professores, uma vez que se observa que esse entendimento está intrinsecamente ligado à concepção de escola e às crenças tradicionais sobre como deve ser esse ambiente: silencioso, com alunos em fila, completamente focados naquilo que o professor tem a dizer. O mesmo cenário se repete quando professores afirmam categoricamente sua preocupação com aquilo que consideram como o uso pedagógico das tecnologias digitais, bem como a manutenção do relacionamento professor-aluno restrito a essas mesmas atividades pedagógicas. Questiona-se: o que define, para esses professores, atividades pedagógicas válidas com 
o uso de mídias digitais de atividades não-pedagógicas? Isso significa que não há aprendizado quando não se trata de uma atividade pedagógica tradicional?

Observou-se que, mesmo cientes dos novos desafios trazidos para a escola e afirmando que a mesma deve se aproximar e acompanhar as mudanças culturais, o foco dos professores parece ser, ainda, a transmissão de conteúdos escolares, apenas propondo a alteração das mídias impressas para as mídias digitais. Isso indica que, embora haja a reprodução do discurso sobre as mudanças culturais por esses professores, a aplicação da tecnologia em sua prática docente parece ser limitada a seu uso ferramental, podendo ou não ser utilizada, sem que haja uma reflexão mais profunda sobre seus impactos culturais.

\section{Inclusão digital, democratização e habilidades para o século XXI}

Ao buscarmos indícios de práticas pedagógicas que englobassem aquelas consideradas as competências e as habilidades estratégicas para o século XXI, como o desenvolvimento do pensamento crítico e da capacidade de solução de problemas, poucas falas tiveram destaque, revelando uma profunda lacuna nesse sentido. Dentre as falas que demonstram a existência da preocupação com o desenvolvimento pleno do cidadão e de suas habilidades críticas com relação ao uso das mídias, destacam-se os depoimentos de três professores:

Eu acho que é importante e acho que o mais interessante é que nós possamos gerar meios para que nossos alunos possam participar nisso. Eles, com as opiniões colaborativas deles, discutam os assuntos e tenham a possibilidade de publicar discussões, opiniões [...] (02.08)

A mídia não é para ser vista passivamente, você tem que ver de maneira crítica e interpretando tudo a luz do que você já percorreu na sua vida [...]. Então acho assim, que um dos papeis do professor é esse, ajudar o aluno a compreender a realidade. (05.02)

$\mathrm{O}$ aluno traz, às vezes, alguma coisa de fora. Ele já vem com a informação, né? E aí a minha prática caminha neste sentido, de mostrar para o aluno como lidar com aquela informação. Como refletir sobre ela. Como ser crítico. Como não aceitar tudo que é colocado para ele como uma verdade real. (05.06) 
É evidente, nessas falas, a percepção da sala de aula como espaço aberto para os alunos serem protagonistas dos procedimentos de ensino-aprendizagem $\mathrm{e}$ desenvolverem habilidades relacionadas à inclusão social no século XXI: lidar com a informação encontrada online, saber opinar sobre os assuntos, ter uma atitude crítica (e ao mesmo tempo respeitosa) sobre os conteúdos online, publicar suas opiniões, entre outras.

Com relação ao potencial colaborativo e à cultura de participação (JENKINS, 2009), há evidências na fala desses professores de que as mídias digitais favorecem o protagonismo dos alunos em diversos momentos, seja com relação ao compartilhamento de informações relevantes entre grupos de alunos ou pesquisando e aprofundando temas vistos em sala de aula, muito embora boa parte dos professores ressalte que esse ainda é um movimento incipiente. Vê-se, ainda, que há discrepâncias entre as oportunidades para que os alunos exerçam seu protagonismo de escola para escola.

\section{É a utilização mesmo dos recursos que eles têm uma prática muito grande. É nesses momentos que eles nos ajudam. Você tem muitas ideias, [...] eles vão lá na Internet procuram e descobrem que tem um monte de aplicativos para fazer aquilo. (03.03)}

Ele falou: "professora queria uma oportunidade para falar sobre a criação de jogos". Porque também é uma forma dele falar, dele se expressar, dele mostrar o que ele gosta de fazer. Dei uma caneta na mão dele, dei o quadro e ele falou. (04.01)

Apesar de as tecnologias digitais apresentarem inúmeras possibilidades de protagonismo juvenil e de desenvolvimento da linguagem, entendida de forma ampla, vemos nesses depoimentos que os usos das mídias feitos pelos professores entrevistados, em sua maioria, não objetivam a participação ativa dos alunos. Ao contrário, muitas vezes a tecnologia é utilizada como amparo de práticas pedagógicas consolidadas, sem o intuito de perseguir a autonomia dos alunos nos usos das mídias. $\mathrm{O}$ dado é interessante, pois parece estar em contradição com os primeiros resultados, apresentados acima. A visão do professor é de que, no geral, o aluno não se beneficia de todas as potencialidades que as tecnologias apresentam. Porém, ao mesmo tempo, em sala de aula ele não está autorizado a utilizar as tecnologias com autonomia, sendo dificultado, assim, o desenvolvimento das habilidades necessárias para a inclusão digital. Reconfirmam-se aqui alguns resultados de pesquisas anteriores que já tinham apontado a tendência da instituição escolar em manter o status quo das práticas pedagógicas, com escassa valorização das possibilidades de protagonismo dos alunos 
(JENKINS, 2006; NAUMANN， 2016; PISCHETOLA， 2016; PISCHETOLA \& HEINSFELD, 2017). Se o jovem não dispõe dos conhecimentos necessários para fazer um "uso adequado" das tecnologias, e se é verdade que a busca por lazer com as tecnologias é muito maior que a busca por outros tipos de conteúdos, como afirmam os professores, não seria papel da escola explorar e aprofundar as possibilidades que a cultura digital apresenta para os jovens e o melhor uso dessas tecnologias?

\section{Considerações finais}

Em um cenário no qual a escola não figura mais como único provedor de conhecimento e informação, percebe-se que, para que se construa um espaço de interação e negociação de sentidos, a educação para a mídia se faz necessária. Assim sendo, é preciso adotar uma pedagogia que favoreça a real compreensão dos diversos produtos culturais, não subestimando quer seus produtores, quer seus receptores (TERUYA, 2009). É sabido que parte da dificuldade em se enfrentar os desafios propostos diz respeito à tradição da pedagogia de transmissão e da linearidade hierárquica estabelecida para os conteúdos (SELWYN, 2011b). Contudo, seria equivocado presumir que as tecnologias digitais, por si só, possam solucionar todos os problemas do sistema educacional vigente, como artefatos místicos. Da mesma forma, compreendê-las apenas por suas dimensões técnicas, sem associá-las à cultura da qual hoje fazemos parte, limitar-se-ia a um reducionismo. É preciso entender que tecnologia, sociedade e cultura caminham juntos; as tecnologias vigentes são sempre fruto de uma cultura, de uma sociedade. A tecnologia pode ser significada, apropriada, ressignificada e transformada pelos indivíduos, na mesma medida em que os transforma (BUZATO, 2010). Essa é a contribuição dos Estudos Culturais para a educação no mundo atual: a reflexão sobre a existência de uma cultura própria da contemporaneidade, que se define como cultura digital.

Questões frequentemente apontadas como soluções garantidas para a educação no século XXI pautam-se na crença da profusão natural da inteligência coletiva, viabilizada pelas conexões virtuais em rede. No entanto, cabe lembrar que os usos das tecnologias são múltiplos, podendo incluir usos mais ou menos proativos ou passivos, mais ou menos colaboradores, mais ou menos autores ou consumidores, contemplando os diversos perfis de alunos existentes (DIMAGGIO et al., 2004). Embora as novas 
mídias de comunicação favoreçam o desenvolvimento colaborativo e a inteligência coletiva, esse comportamento não é automaticamente determinado por elas, algo claramente observado nos discursos dos professores entrevistados. Com isso, ressalta-se que a verdadeira revolução tecnológica do século XXI não é representada meramente por uma vultuosa quantidade de artefatos eletrônicos disponibilizados e integrados ao cotidiano de cada indivíduo, mas, fundamentalmente, por novas relações entre processos simbólicos e culturais de nossa época, como apontado pelos Estudos Culturais.

Ao analisarmos as falas dos professores, nota-se que há um distanciamento cultural percebido pelos professores entre si e os alunos no que tange à temática das mídias digitais. Indo além, os professores também observam que a mesma distância se coloca entre a cultura dos alunos e uma cultura escolar. A cultura do aluno aparece no discurso dos professores entrevistados como a cultura das mídias digitais, da agilidade, do nativismo digital (PRENSKY, 2013) e do lazer "sem limites" possibilitado por essas mídias. A dos professores, uma cultura erudita e normativa, traduzida na identificação do que consideram como comportamentos errados com relação ao uso das mídias digitais e na prescrição de comportamentos considerados adequados. O eruditismo declarado por parte dos professores é associado ao que corresponderia à "verdadeira cultura", em detrimento daquilo o que os alunos vivem em seu cotidiano, sendo suas práticas entendidas como frutos da "falta de cultura". Já a cultura da escola é relacionada, na fala desses professores, à disciplina, ordem, silêncio, obrigação e transmissão de conteúdo, e, às vezes, responsável pela mediação das relações com as tecnologias digitais. Interessante fato é que o caráter prescritivo com relação às mídias digitais emerge na fala dos entrevistados na mesma medida em que é alegada maior familiaridade com mídias impressas, como enciclopédias e dicionários. Isso nos leva a crer que, embora hoje entenda-se a cultura como um conjunto de processos sociais, relacionando significações e ressignificações, na fala desses professores há o resquício da distinção anterior entre cultura e civilização, com raízes na segregação entre determinados valores e gostos considerados dignos de difusão e os demais, considerados inferiores (CANCLINI, 2005). O mesmo é levado para a relação entre professor e aluno online, em que o posicionamento da maior parte dos professores é contrário à manutenção dessa relação ou parcialmente a favor, desde que resguardados os seus respectivos papéis. 
Quanto às práticas pedagógicas cotidianas, embora citado expressivamente, o uso de vídeos com fins didáticos não supre todas as lacunas encontradas na inclusão das mídias digitais no âmbito escolar. Outra profunda lacuna é encontrada no que diz respeito à utilização das mídias digitais em consonância com o desenvolvimento das habilidades entendidas como necessárias ao século XXI, como o desenvolvimento do pensamento crítico e da habilidade de solução de problemas.

Cabe reforçar que os professores entrevistados estão lotados em escolas consideradas pela SME-RJ como pioneiras no uso das mídias digitais em seu cotidiano escolar. Em diversas oportunidades, esses professores ressaltaram que suas práticas pedagógicas quanto ao uso das mídias diferem de uma escola para outra, dadas as diferenças no acesso e no estímulo por parte da gestão. Com isso, nos perguntamos se o protagonismo dos alunos quanto à colaboração e à cultura de participação também são alterados, sofrendo influência desses ambientes, abrindo espaço para demais estudos comparativos. Ainda quanto à visão de escola dos professores, como comentado, questiona-se se é possível superar os desafios colocados pela cultura digital no ambiente escolar sem que haja uma mudança no entendimento de como deve ser esse ambiente. Há, no panorama da cultura digital, espaço para carteiras enfileiradas e alunos passivos, receptores do conteúdo narrado pelo professor? Ou esse tipo de escola está fadado a perecer?

\section{REFERÊNCIAS}

BANNELL, R.; DUARTE, R.; CARVALHO, M. C.; PISCHETOLA, M.; MARAFON, G.; CAMPOS, G. H. B. de. Educação no século XXI: cognição, tecnologias e aprendizagens. Petrópolis/Rio de Janeiro: Vozes/PUC-Rio, 2016.

BARATTO, S. S.; CRESPO, L. F. Cultura digital ou cibercultura: definições e elementos constituintes da cultura digital, a relação com aspectos históricos e educacionais. Rev. Científica Eletrônica UNISEB, Ribeirão Preto, v. 1, n. 2, p. 16-25, ago./dez. 2013.

BORTOLAZZO, S. F. O imperativo da cultura digital: entre novas tecnologias e estudos culturais. Revista Cadernos de Comunicação, Santa Maria, v.20, n.1, art 1, p.1-24, jan./abr. 2016.

BUZATO, M. Cultura digital e apropriação ascendente: apontamentos para uma educação 2.0. Educação em Revista, Belo Horizonte, v. 26, n. 3, p. 283-303, dez. 2010. Disponível em <http://www.scielo.br/scielo.php?script=sci_arttext\&pid=S010246982010000300014>. Acesso em 23 jun. 2016 
CANCLINI, N. G. Diferentes, desiguales y desconectados. Mapas de la interculturalidad. Barcelona: Gedisa, 2005.

CASSIANI, S. D. B.; CALARI, M. H. L.; PELÁ, N. T. R. A teoria fundamentada nos dados como abordagem da pesquisa interpretativa. In Revista latino-americana de enfermagem, v. 4. n. 3, p. 75-88, dezembro de 1996.

CASTELlS, M. A sociedade em rede. São Paulo: Paz e Terra, 1999.

CAZELOTO, E. Apontamentos sobre a noção de "democratização da internet". In: TRIVINHO, E., CAZELOTO, E. A cibercultura e seu espelho: campo de conhecimento emergente e nova vivência humana na era da imersão interativa. São Paulo: ABCiber; Instituto Itaú Cultural, 2009.

COSTA, M. V., SILVEIRA, R. H., SOMMER, L. H. Estudos culturais, educação e pedagogia. Revista Brasileira de Educação, n. 23, p. 36-61, mai./jun./jul./ago. 2003.

DIMAGGIO, P.; HARGITTAI, E.; CELESTE, C.; SHAFER, S. From unequal access to differentiated use: A literature review and agenda for research on digital inequality. In: NECKERMAN, K. Social inequality. New York: Russell Sage, 2004.

GABRIEL, M. Educ@r: a (r)evolução digital na educação. São Paulo: Saraiva, 2013.

GEE, J.P.; HAYES, E. R. Language and Learning in the Digital Age. London: Routledge, 2011.

HALL, S. A centralidade da cultura: notas sobre as revoluções culturais do nosso tempo. Educação \& Realidade, Porto Alegre, v. 22, n. 2, p. 15-46, jul./dez. 1997.

JENKINS, H. Confronting the challenges of participatory culture: media education for the $21^{\text {st }}$ Century. Illinois: MacArthur Foundation Reports on Digital Media and Learning, 2009.

JENKINS, H. Convergence Culture: Where Old and New Media Collide, New York University Press, New York, 2006.

LEMKE, J. L. Letramento metamidiático: transformando significados e mídias. Trab. Ling. Aplic., Campinas, v. 49, n. 2, p. 455-479, jul./dez. 2010.

LEMOS A. A cibercultura como território recombinante. In: Trivinho E, Cazeloto E (org.). A cibercultura e seu espelho: campo de conhecimento emergente e nova vivência humana na era da imersão interativa. São Paulo: ABCiber, 2009.

LESSIG, L. Remix: making art and commerce thrive in the hybrid economy. New York: The Penguin Press, Penguin Group, 2008.

LÉVY, P (1999). Cibercultura. São Paulo: Editora 34, 2014.

NAUMANN, L. A. Multiletramentos na sala de aula: entre a intuição e a intencionalidade. Dissertação de mestrado, PPGE PUC-Rio, 2016. 
PISCHETOLA, M. Inclusão digital e educação: a nova cultura da sala de aula. Petrópolis: Vozes, Rio de Janeiro: PUC-Rio, 2016.

PISCHETOLA, M; HEINSFELD, B. Tecnologias, estilo motivacional do professor e democracia em sala de aula. In: IX Seminário Internacional. As Redes Educativas e as Tecnologias, UERJ, Rio de Janeiro, 05 a 08 de junho de 2017.

PRENSKY, M. From digital natives to digital wisdom: hopeful essays for $21 \mathrm{st}$ Century Learning. USA: Corwin; 2013.

PRETTO, N.; PINTO, C. Tecnologias e novas educações. Revista Brasileira de Educação, Rio de Janeiro, v. 11, n. 31, jan./abr. 2006.

SELWYN, N. Education and technology: Key issues and debates. London: Continuum, 2011a.

SELWYN, N. Em defesa da diferença digital: uma abordagem crítica sobre os desafios curriculares da web 2.0. In: DIAS, P. \& Osório, A. (Orgs.). Aprendizagem (in)formal na web Social. Braga: Centro de Competência da Universidade do Minho, 2011b, p. $35-61$.

TERUYA, T. K. Sobre mídia, educação e Estudos Culturais. In. MACIEL, Lizete Shizue Bomura; MORI, Nerli Nonato Ribeiro (Org.) Pesquisa em Educação: Múltiplos Olhares. Maringá: Eduem, 2009. p. 151-165.

UGARTE, D. de. O poder das redes: manual ilustrado para pessoas, organizações e empresas, chamadas a praticar o ciberativismo. Porto Alegre: EDIPUCRS, 2008.

\section{Como referenciar este artigo}

HEINSFELD, Bruna Damiana; PISCHETOLA, Magda. Cultura digital e educação, uma leitura dos Estudos Culturais sobre os desafios da contemporaneidade. Revista IberoAmericana de Estudos em Educação, Araraquara, v. 12, n. esp. 2, p. 1349-1371, ago./2017. Disponível em: <http://dx.doi.org/10.21723/riaee.v12.n.esp.2.10301>. EISSN: 1982-5587.

Submetido em: 10/04/2017

Aprovação final em: 28/07/2017 